\title{
KARAKTER TOKOH DALAM NOVEL LANGIT MEKAH BERKABUT MERAH KARYA GEIDURRAHMAN AL-MISHRY BERBASIS NILAI-NILAI KARAKTER RELIGIUS DAN IMPLIKASINYA DALAM PEMBELAJARAN SASTRA DI MADRASAH ALIYAH
}

\author{
Aida Azizah ${ }^{\bowtie}$,Leli Nisfi Setiana \\ Prodi Pendidikan Bahasa dan Sastra Indonesia, Fakultas Keguruan dan Ilmu Pendidikan \\ Universitas Islam Sultan Agung, Semarang, Indonesia
}

\section{Info Artikel}

Sejarah Artikel: Diterima September 2016 Disetujui November 2016 Dipublikasikan Desember 2016

Keywords:

characters, the values of religious character, and instructional literature.

\author{
Abstract \\ Novel Langit Mekah Berkabut Merah work is a novel that has a lot of wisdom about religious \\ values. Religious value of these figures seen in the overall story is actualized through the elements \\ of the literary works of the builders. Author of the novel tells the story using language that is easy \\ to understand and use easily understandable story line. The background of the story in the novel is \\ parallel to the background of the life of the students, so that religious values can be utilized in the \\ teaching of literature in class XII SMA / MA.
}

\begin{abstract}
Novel Langit Mekah Berkabut Merah karya Geidurrahman Al-Mishry merupakan novel yang memiliki banyak hikmah tentang nilai-nilai religius. Nilai religius tokoh-tokoh tersebut terlihat dalam keseluruhan cerita yang teraktualisasikan melalui unsur-unsur pembangun karya sastra. Pengarang novel ini menceritakan kisahnya menggunakan bahasa yang mudah dipahami dan menggunakan alur cerita yang mudah dimengerti. Latar belakang cerita dalam novel ini sejajar dengan latar belakang kehidupan peserta didik, sehingga nilai-nilai religius tersebut dapat dimanfaatkan dalam pembelajaran sastra di kelas XII SMA/MA.
\end{abstract}

(C) 2016 Universitas Muria Kudus

Alamat korespondensi:

Program Studi Pendidikan Guru Sekolah Dasar

p-ISSN 2087-9385

Fakultas Keguruan dan Ilmu Pendidikan Universitas Muria Kudus

e-ISSN 2528-696X

Kampus UMK Gondangmanis, Bae Kudus Gd. L. 1t I PO. BOX 53

Kudus

Tlp (0291) 438229 ex.147 Fax. (0291) 437198

E-mail: aidaazizah@unissula.ac.id 


\section{PENDAHULUAN}

Novel tidak saja menjadi karya rekaan semata, tetapi bisa menjadi referensi atau bacaan untuk memahami kebudayaan suatu masyarakat. Novel juga dapat digunakan dalam pembelajaran sastra di sekolah, hal ini sesuai dengan Kurikulum 2013, yaitu Pembelajaran Sastra di SMA/MA kelas XII semester dua. Dalam Kompetensi Dasar 3.1 "Memahami struktur dan kaidah teks novel baik melalui lisan maupun tulisan." dan 4.1 "Menginterpretasi makna teks novel baik secara lisan maupun tulisan". Dengan adanya Kompetensi Dasar tersebut, pendidik dapat memanfaatkan novel Novel Langit Mekah Berkabut Merah Karya Geidurrahman Al- Mishry sebagai bahan pembelajaran sastra. Novel tersebut bisa digunakan sebagai bahan pembelajaran di sekolah untuk menambah wawasan siswa mengenai novel Indonesia.

Novel Langit Mekah Berkabut Merah karya Geidurrahman Al-Mishry merupakan salah satu novel yang memiliki hikmah dan penuh dengan nilai-nilai religius. Nilai karakter religius disampaikan melalui peran tokoh-tokoh yang terdapat dalam novel, hal itu terlihat dalam keseluruhan cerita yang teraktualisasikan melalui unsur-unsur pembangun karya sastra. Bahasa yang digunakan pengarang dalam Novel Langit Mekah Berkabut Merah karya Geidurrahman AlMishry menggunakan bahasa yang mudah dipahami dan menggunakan alur cerita yang mudah dimengerti oleh peserta didik. Selain itu, latar belakang cerita dalam novel ini sejajar dengan latar belakang kehidupan peserta didik dalam kehidupan sehari-hari.

Pendidikan di Indonesia sekarang ini masih menekankan pada pendidikan karakter siswa. Analisis mengenai nilai religius dalam Novel Langit Mekah Berkabut Merah karya Geidurrahman Al-Mishry yang dilakukan sangat berkaitan dengan tujuan pembentukan karakter peserta didik. Hal tersebut dapat terwujud ketika nilai religius yang terdapat dalam novel tersebut telah diketahui dan mampu dipahami, sehingga guru atau peserta didik akan menjadikan nilainilai religius untuk diterapkan dalam kehidupan sebagai penyesuaian diri terhadap lingkungannya dalam menjalani hidup bermasyarakat. Dengan demikian sedikit demi sedikit karakter masingmasing peserta didik akan muncul sesuai kemampuannya masing-masing ketika memahami novel Novel Langit Mekah Berkabut Merah karya Geidurrahman Al-Mishry.

Berdasarkan hal tersebut, hasil kajian novel Langit Mekah Berkabut Merah karya Geidurrahman Al- Mishry yang berbasis nilainilai karakter religius jika dikaitkan dan dijadikan materi/bahan pembelajaran sastra di sekolah sangat relevan. Relevansi novel "Langit Mekah Berkabut Merah karya Geidurrahman AlMishry" sebagai materi/bahan pembelajaran sastra di SMA/MA yang sesuai dengan kurikulum 2013.

\section{METODE PENELITIAN}

Penelitian yang digunakan adalah penelitian deskriptif kualitatif. Penelitian deskriptif kualitatif yakni penelitian dengan data yang dikumpulkan berupa kata-kata, gambar, dan bukan angka-angka melainkan dalam bentuk kualitatif dan semua yang dikumpulkan menjadi kunci terhadap apa yang diteliti (Moleong, 1988: 6). Dalam penelitian ini metode yang digunakan adalah metode deskriptif, yakni metode ini digunakan untuk mendeskripsikan atau menjelaskan data-data yang diperoleh dalam penelitian karakter tokoh dalam novel Langit Mekah Berkabut Merah dan implikasinya terhadap pengajaran sastra di SMA/MA.

\section{PEMBAHASAN}

a. Novel

Novel adalah sebuah karya fiksi prosa yang ditulis secara naratif; biasanya dalam bentuk cerita. Penulis novel disebut novelis. Kata novel berasal dari bahasa Italia novella yang berarti "sebuah kisah atau sepotong berita". Novel lebih panjang (setidaknya 40.000 kata) dan lebih kompleks dari cerpen, dan tidak dibatasi keterbatasan struktural dan metrikal sandiwara atau sajak. Umumnya sebuah novel bercerita tentang tokoh-tokoh dan perilaku mereka dalam kehidupan sehari-hari.

Aminudin (2004: 32) bahwa novel merupakan karya fiksi yang mengungkapkan aspek-aspek kemanusiaan yang lebih mendalam dan disajikan dengan halus. Novel yang diartikan dapat memberikan konsentrasi kehidupan yang lebih tegas, dengan roman yang diartikan rancangannya lebih luas mengandung sejarah perkembagan yang biasanya terdiri dari beberapa fragmen dan patut ditinjau kembali.

\section{b. Unsur-Unsur Novel}

Unsur novel dibagi menjadi dua, yaitu unsur intrinsik dan unsur ekstrinsik. Unsur intrinsik novel adalah unsur yang langsung 
membangun novel tersebut dan berada di dalam novel tersebut. Sedangkan, unsur ekstrinsik novel adalah unsur yang berada di luar novel tersebut. Unsur ekstrinsik tidak berhubungan secara langsung dalam membangun suatu novel.

1. Unsur intrinsik novel

Unsur intrinsik adalah unsur yang membangun karya sastra itu sendiri yang menyebabkan karya itu hadir, unsur intrisik terdiri dari berikut:

a. Tema adalah ide dasar atau gagasan pokok yang mendasari novel.

b. Alur adalah rangkaian peristiwa demi peristiwa dalam novel.

c. Tokoh serta perwatakan berkaitan dengan pelaku dalam novel.

d. Sudut Pandang adalah cara penulis novel menceritakan kisahnya atau segi pandang penulis dalam membawakan cerita. Sudut pandang berkaitan dengan penggunaan kata ganti dalam bercerita oleh penulis. apakah menggunakan kata ganti orang pertama, orang kedua, atau orang ketiga.

e. Latar adalah tempat dan waktu terjadinya cerita dalam novel.

f. Gaya Bahasa berkaitan dengan penggunaan bahasa oleh penulis dalam novel tersebut.

g. Amanat adalah pesan yang terkandung dalam novel. Pesan tersebut umumnya merupakan ajaran moral yang bersifat mendidik.

2. Unsur ekstrinsik dalam novel.

Unsur ekstrinsik adalah unsur yang membangun karya sastra dari luar. Yang termasuk dalam unsur ekstrinsik adalah: psikologi, social, budaya, filsafat, serta lingkungan dan agama.

\section{c. Pendidikan Karakter}

Pendidikan karakter bertujuan mengembangkan nilai-nilai yang membentuk karakter bangsa yaitu Pancasila, meliputi : (1) mengembangkan potensi peserta didik agar menjadi manusia berhati baik, berpikiran baik, dan berperilaku baik; (2) membangun bangsa yang berkarakter Pancasila; (3) mengembangkan potensi warga negara agar memiliki sikap percaya diri, bangga pada bangsa dan negaranya serta mencintai umat manusia.

Pendidikan karakter dilakukan melalui berbagai media, diantaranya dalam kegiatan pendidikan. Satuan pendidikan sebenarnya selama ini sudah mengembangkan dan melaksanakan nilai-nilai pembentuk karakter melalui program operasional satuan pendidikan masing-masing. Hal ini merupakan prakondisi pendidikan karakter pada satuan pendidikan yang untuk selanjutnya diperkuat dengan 18 nilai hasil kajian empirik Pusat Kurikulum. Nilai prakondisi yang dimaksud meliputi religius, jujur, toleransi, disiplin, kerja keras, kreatif, mandiri, demokratis, rasa ingin tahu, semangat kebangsaan, cinta tanah air, menghargai prestasi, bersahabat/ komunikatif, cinta damai, gemar membaca, peduli lingkungan, peduli sosial, dan tanggung jawab.

d. Karakter Tokoh dalam Novel Langit Mekah Berkabut Merah Karya Geidurrahman Al- Mishry.

Berpijak dari penelitian yang telah dilakukan, dalam Novel Langit Mekah Berkabut Merah Karya Geidurrahman Al- Mishry terdapat dua tokoh utama dan enam belas tokoh bawahan. Karakter dari masing-masing tokoh tersebut akan diuraikan sebagai berikut.

\section{Tokoh Utama}

\begin{tabular}{|l|l|l|}
\hline No & $\begin{array}{l}\text { Nama } \\
\text { Tokoh }\end{array}$ & \multicolumn{1}{|c|}{ Karakter } \\
\hline 1 & Firdaus & $\begin{array}{l}\text { suka menolong, kurang } \\
\text { sabar, suka memuji, suka } \\
\text { bercanda, bertanggung } \\
\text { jawab, suka menggombal, } \\
\text { berbohong, agak sombong, } \\
\text { mudah cemas, penyedih, } \\
\text { mudaah tergiur kemewahan, } \\
\text { mudah ragu, pandai } \\
\text { membujuk, membalas budi, } \\
\text { dan sulit mengendalikan } \\
\text { amarah }\end{array}$ \\
\hline 2 & Midah & $\begin{array}{l}\text { suka mencemaskan orang } \\
\text { lain, suka disayangi, rela } \\
\text { berkorban, patuh, sederhana, } \\
\text { berkeyakinan teguh, } \\
\text { perpendirian teguh, sabar, } \\
\text { mudah sedih, rajin, kurang } \\
\text { percaya diri, lugu, senantiasa } \\
\text { bersyukur, taat, nekat, } \\
\text { menimbang rasa, mudah } \\
\text { gugup, dan tabah }\end{array}$ \\
\hline
\end{tabular}




\section{Tokoh Bawahan}

\begin{tabular}{|c|c|c|}
\hline No & Nama Tokoh & Karakter \\
\hline 1 & Abuya & $\begin{array}{l}\text { berperilaku negative dan } \\
\text { tidak taat }\end{array}$ \\
\hline 2 & Bogul & perhatian dan peduli \\
\hline 3 & $\begin{array}{l}\text { Dina } \\
\text { Octaviola }\end{array}$ & $\begin{array}{l}\text { suka merajuk, manja } \\
\text { dan suka berkata ketus }\end{array}$ \\
\hline 4 & $\begin{array}{l}\text { Effendi } \\
\text { Muthahar }\end{array}$ & pengertian dan peduli \\
\hline 5 & Erni & $\begin{array}{l}\text { temperamental dan } \\
\text { boros }\end{array}$ \\
\hline 6 & Fatin & tidak bermoral \\
\hline 7 & Gamal & $\begin{array}{l}\text { ramah, sopan dan suka } \\
\text { memuji }\end{array}$ \\
\hline 8 & Hermansyah & $\begin{array}{l}\text { sopan, ramah, dan } \\
\text { kurang peduli }\end{array}$ \\
\hline 9 & $\begin{array}{l}\text { Huhartini } \\
\text { (Dokter } \\
\text { Tien) } \\
\end{array}$ & suka bercanda \\
\hline 10 & Irfan & $\begin{array}{l}\text { bersahaja, berpendirian } \\
\text { teguh, religius, memiliki } \\
\text { jiwa bakti dan } \\
\text { pengabdian, tegas dan } \\
\text { disiplin }\end{array}$ \\
\hline 11 & Junaidi & $\begin{array}{l}\text { kasar, pemarah, } \\
\text { pembohong, pemfitnah } \\
\text { dan pencenburu }\end{array}$ \\
\hline 12 & Khalid & Berperilaku negative \\
\hline 13 & $\begin{array}{l}\text { Madam } \\
\text { Syaima }\end{array}$ & $\begin{array}{l}\text { kasar, suka marah, suka } \\
\text { memukul dan judes }\end{array}$ \\
\hline 14 & $\begin{array}{l}\text { Marwan } \\
\text { Lubis }\end{array}$ & \begin{tabular}{lrr} 
pandai & \multicolumn{2}{c}{ membujuk, } \\
pemurah, tidak mudah \\
menyerah dan setia \\
kawan
\end{tabular} \\
\hline 15 & Ubed & $\begin{array}{l}\text { ulet, suka bercanda, } \\
\text { setia kawan, ulet, tegas, } \\
\text { simpatik dan peduli }\end{array}$ \\
\hline 16 & Yuyun & $\begin{array}{l}\text { sabar, berprasangka } \\
\text { baik, bertawakal, dan } \\
\text { istiqomah }\end{array}$ \\
\hline
\end{tabular}

\section{e. Nilai-nilai Karakter Religius dalam Novel Langit Mekah Berkabut Merah karya Geidurrahman Al- Mishry}

Religi merupakan suatu kesadaran yang menggejala secara mendalam dalam lubuk hati manusia sebagai human nature. Religi tidak hanya menyangkut segi kehidupan secara lahiriah melainkan juga menyangkut keseluruhan diri pribadi manusia secara total dalam integrasinya hubungan ke dalam keesaan Tuhan (Rosyadi, 1995: 90).

Islam mengandung ajaran yang komperehensif, mengatur hubungan antara berbagai aspek. Islam tidak hanya mengatur hubungan manusia dengan Tuhannya, tetapi juga mengatur hubungan antara sesamanya dan hubungannya dengan alam. Dalam kaitan dengan hal tersebut ajaran Islam terbagi atas tiga bagian yaitu: Akidah, ibadah, dan akhlak.

\section{Akidah}

Menurut bahasa akidah berasal dari al'aqdu artinya ikatan yang kuat. Bisa pula berarti kepercayaan yang kokoh. Ikatan janji, kadang juga disebut aqdun. Sesuatu yang bisa membuat hati seseorang menjadi terikat kuat dan pasti padanya, disebut aqidah. Adapun nilai akidah yang terdapat dalam Novel Langit Mekah Berkabut Merah Karya Geidurrahman Al- Mishry antara lain sebagai berikut.

\begin{tabular}{|c|c|}
\hline Kutipan & Keterangan \\
\hline 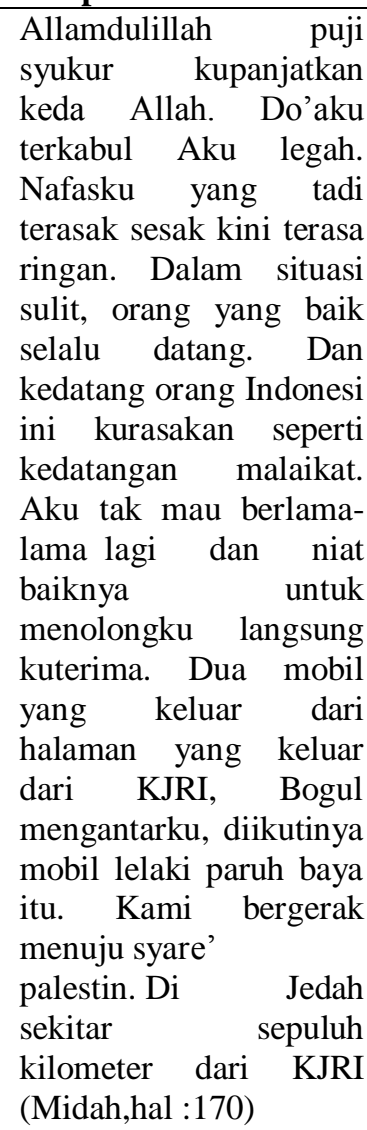 & \begin{tabular}{l}
\multicolumn{3}{l}{ kutipan } \\
teks menggambarka \\
$\mathrm{n}$ bahwa Midah \\
sangat merasa \\
bersyukur karena apa \\
yang $\quad$ menjadi \\
keingianaya telah \\
terkabul dan ia \\
sangat senang karena \\
dalam situasi yang \\
sangat sulit akhirnya \\
pada saat itu \\
pertolongan Allah \\
datang kepadanya
\end{tabular} \\
\hline
\end{tabular}




\section{Ibadah}

Secara umum ibadah merupakan bukti manusia kepada Allah swt, karena didorong dan dibangkitkan oleh kadidah tauhid, sedangkan secara khusus ibadah adalah bertaqarrub (mendekatkan diri) kepada Allah, dengan jalan mentaati segala perintag-Nya, menjauhi larangannya dan mengamalkan segala yang diizinkan Allah. Adapun nilai ibadah yang terdapat dalam Novel Langit Mekah Berkabut Merah Karya Geidurrahman Al- Mishry antara lain sebagai berikut.

\begin{tabular}{|c|c|}
\hline Kutipan & Keterangan \\
\hline 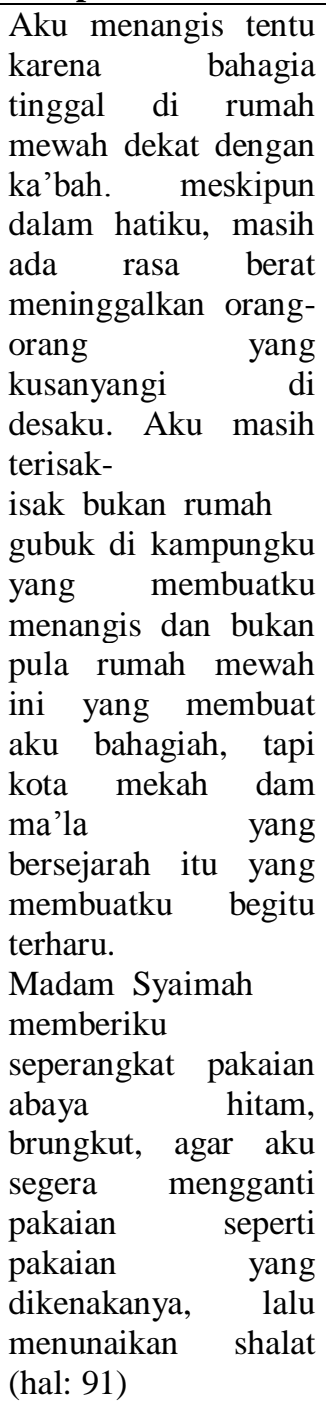 & $\begin{array}{l}\text { Kutipan teks } \\
\text { menggambarkan rasa } \\
\text { syukurnya kepada } \\
\text { Allah karena ia telah } \\
\text { mendapatkan } \\
\text { kesenangan dan rezeki } \\
\text { yang besar. Jika kita } \\
\text { tidak bisa } \\
\text { mengendalikan } \\
\text { emosi karena } \\
\text { kesenangan yang } \\
\text { berlebihan kita bisa } \\
\text { tegoda oleh } \\
\text { kemewahan dunia. } \\
\text { Karena sebetulnya } \\
\text { sifat sabar tidak hanya } \\
\text { diperlukan ketika kita } \\
\text { menghadapi kesulitan. } \\
\text { Tapi juga pada saat } \\
\text { kita mendapatkan } \\
\text { kesenangan dan } \\
\text { keberhasilan. } \\
\text { diperlukan dan Inilah } \\
\text { yang diperintahkan } \\
\text { Allah untuk selalu } \\
\text { meminta pertolongan } \\
\text { kepadanya dengan } \\
\text { sabar dan shalat. Insya } \\
\text { Allah jika kita bisa } \\
\text { melakukannya secara } \\
\text { istiqamah, niscaya } \\
\text { Allah akan selalu } \\
\text { bersama kita }\end{array}$ \\
\hline
\end{tabular}

\section{Akhlak}

Secara etimologis (bahasa Arab) akhlak adalah bentuk jamak dari khuluq yang berarti budi pekerti, perangkai, tingkah laku, atau tabiat. Adapun nilai Akhlak yang terdapat dalam Novel Langit Mekah Berkabut Merah Karya Geidurrahman Al- Mishry antara lain sebagai berikut.

\begin{tabular}{|c|c|}
\hline Kutipan & Keterangan \\
\hline $\begin{array}{l}\text { Midah, semakin besar } \\
\text { dan kokoh iman } \\
\text { seseorang , semakin } \\
\text { besar dan kokoh pula } \\
\text { ujiannya. "dilain } \\
\text { kesempatan ayahnya } \\
\text { juga berpesan" jangan } \\
\text { sampai penderitaan } \\
\text { hidup kita di dunia ini } \\
\text { menjadikan kita } \\
\text { merasa Allah tidak } \\
\text { berbuat adil pada kita. } \\
\text { justru sebalikanya } \\
\text { denga berbagai cobaan } \\
\text { hidup yang berat } \\
\text { itulah Allah } \\
\text { menunjukan kasih } \\
\text { sayang-Nya. Karnena } \\
\text { itu, setiap orang harus } \\
\text { harus sabar dan } \\
\text { bersyukur (Midah, hal: } \\
\text { 103) }\end{array}$ & $\begin{array}{l}\text { Kutipan di } \text { atas } \\
\text { mengambarkan betapa } \\
\text { besarnya peranan ayah } \\
\text { dalam mendidik anak- } \\
\text { anaknya supaya ia } \\
\text { tumbuh menjadi anak } \\
\text { yang kuat dalam } \\
\text { menghadipi segala } \\
\text { cobaan hidup dan } \\
\text { inilah cerminan orang } \\
\text { yang bisa dijadikan } \\
\text { teladan karena } \\
\text { senantiasa } \\
\text { mengindahkan nasehat } \\
\text { orang tuanya. Dalam } \\
\text { kutipan di atas seorang } \\
\text { ayah yang menasehati } \\
\text { Midah selalu mengajak } \\
\text { kita bersabar dan } \\
\text { bersyukur. } \\
\text { (dari kutipan nilai } \\
\text { akhlak mengajarkan } \\
\text { kita agar tetap optimis } \\
\text { dalam menhadapi } \\
\text { segala masalah hidup } \\
\text { yang kita alami karena } \\
\text { dalam setiap } \\
\text { perjuangan } \\
\text { pengorbanan } \\
\text { Allah pasti } \\
\text { membalasnya dengan } \\
\text { yang lebih baik) }\end{array}$ \\
\hline
\end{tabular}

\section{f. Implikasi dalam Pembelajaran Sastra di SMA/MA}

Implikasi nilai-nilai religius dalam Novel Langit Mekah Berkabut Merah Karya Geidurrahman Al- Mishry terdapat dalam Kurikulum 2013, yaitu Pembelajaran Sastra di SMA kelas XII semester dua. Dalam Kompetensi Dasar 3.1 yang berbunyi "Memahami struktur dan kaidah teks novel baik melalui lisan maupun tulisan." dan 4.1 yang berbunyi "Menginterpretasi makna teks novel baik secara lisan maupun tulisan". Dengan adanya Kompetensi Dasar tersebut, pendidik dapat memanfaatkan novel Novel Langit Mekah Berkabut Merah Karya 
Geidurrahman Al- Mishry sebagai bahan pembelajaran.

Dalam novel tersebut terdapat tiga nilai religius yang dapat dijadikan contoh oleh siswa dan digunakan dalam kehidupan sehari-hari, yaitu akidah, akhlak, dan ibadah. Banyak fenomena yang terjadi dalam kehidupan kita yang terkadang kita merasa sangat sulit menghadapinya itu karena kurangnya ilmu yang kita dapatkan sehingga kita selalu merasakan kegelisahan dan kesalahan dalam menjalankan ibadah, hal ini seiring bertambahnya usia kita yang menimbulkan adanya dorongan untuk lebih meningkatkan kualitas keagamaan yang merupakan petuah dan petunjuk dalam menjalani kehidupan beragama.

\section{SIMPULAN}

a. Simpulan

Karakter tokoh religius dalam novel langit mekah berkabut merah karya Geidurrahman AlMishry dideskripsikan dalam tiga jenis nilai religius, yaitu akidah, akhlak, dan Ibadah. Novel tersebut dapat dimanfaatkan sebagai bahan pembelajaran dalam Kurikulum 2013, di Sekolah Menengah Atas atau Madrasah Aliyah kelas XII semester dua. Implikasi nilai-nilai karakter religius dititikberatkan pada sumber bahan ajar yang mengacu pada tujuan pengajaran sastra. Implikasi nilai-nilai tersebut sangat baik digunakan untuk penyesuaian diri siswa terhadap lingkungannya. Di sekolah, seorang siswa harus mampu memahami mengenai nilai religius tersebut untuk bekal dirinya dalam menjalani hidup bermasyarakat.

b. Saran

Hasil penelitian masih belum lengkap sehingga dapat menjadi bahan acuan untuk penelitian selanjutnya. Penelitian ini juga dapat digunakan sebagai sumbangan dalam pengembangan di dunia pendidikan terutama dibidang sastra. Dari hasil analisis karakter tokoh dalam novel langit mekah berkabut merah karya geidurrahman al-mishry berbasis nilai-nilai karakter religius sangatlah berguna untuk pengembangan bahan ajar, khususnya terhadap pengajaran sastra SMA/MA.

\section{DAFTAR PUSTAKA}

Aminuddin. 1999. Stilistika: Pengantar

Memahami dalam Karya

Sastra. IKIP Semarang Press.

Semarang.

2004. Pengantar Apresiasi Karya

Sastra. Bandung: Sinar Baru

Algesindo

Balitbang Puskur. 2010. Pengembangan Pendidikan Budaya dan Karakter Bangsa: Pedoman Sekolah. Jakarta: Kemdiknas Balitbang Puskur.

Kemendikbud. 2013. Permendikbud No.81A tentang Implementasi Kurikulum. Jakarta: Kementerian Pendidikan dan Kebudayaan.

Kemendiknas. 2010. Pendidikan Karakter Terintegrasi dalam Pembelajaran di Sekolah Menengah Atas. Jakarta: Puskur-Balitbang,

Kemdiknas

Rahmanto, B. 1988. Metode Pengajaran Sastra. Yogyakarta: Kanisius

Lickona, Thomas. 1991. Educating for Character: How Our School Can Teach Respect and Responsibility. New York: Bantam Books.2004.

Mulyati, Yeti. 2000. Pendidikan Bahasa dan Sastra Indonesia di Kelas Tinggi. Jakarta: Universitas Terbuka.

Moleong, Lexy J. 2002. Metodologi Penelitian Kualitatif. Bandung: PT Remaja Rosdakarya.

Nurgiantoro, Burhan. 2005. Teori Pengkajian Fiksi. Yogyakarta: UGM Press. 